\title{
RANCANG BANGUN GAME PUZZLE THE TABPERI DENGAN ALGORITME A* BERBASIS ANDROID
}

\author{
F Melati $^{*}$, A Putri Sujana ${ }^{2}$, S Nurhayati ${ }^{3}$
}

1,3) Sistem Komputer, Fakultas Teknik dan Ilmu Komputer, Universitas Komputer Indonesia

Jl. Dipati Ukur No. 112 - 116, Bandung, Indonesia 40132

2) Teknologi Rekayasa Multimedia Fakultas Ilmu Terapan

Jl. Telekomunikasi No.1, Sukapura, Kec. Dayeuhkolot, Bandung, Jawa Barat 40257

*mail : fenimelati16@mahasiswa.unikom.ac.id

(Naskah masuk: 12 Nopember 2021; diterima untuk diterbitkan: 2 April 2021)

\begin{abstract}
ABSTRAK - Unsur kimia merupakan mata pelajaran dalam sekolah tingkat menengah atas. Namun, tabel unsur kimia yang bersifat abstrak seringkali membuat siswa menjadi malas dalam menghafal dan mengingat suatu tabel periodik unsur kimia. Untuk membantu para siswa, salah satunya dengan cara memanfaatkan perkembangan teknologi dengan membuat aplikasi game edukasi dalam bentuk game puzzle 2 dimensi. Program aplikasi ini dimaksudkan untuk membantu siswa dalam mengasah daya ingat pada tabel periodik unsur kimia dengan cara menyusun susunan tabel yang telah di acak menjadi sebuah tabel yang utuh. Pengguna dapat memilih level permainan secara bebas sesuai dengan yang diinginkan. Program menggunakan algoritme a-star dan menerapkan metode heuristik. Algoritme a-star dapat menyelesaikan permasalahan secara optimal untuk menemukan jalan terpendek menuju tujuan. Penerapan metode heuristik digunakan untuk menyortir secara langsung hasil yang didapat tanpa harus menyusuri semua jalan lintasan. Hasil pengujian menunjukan semua fitur dan penerapan algoritme dalam aplikasi game ini sudah berjalan dengan semestinya serta dapat membantu pengguna dalam mempelajari unsur kimia.
\end{abstract}

Kata Kunci - Algoritme A-star, Game Puzzle, Tabel Periodik Unsur Kimia.

\section{DESIGN OF THE TABPERI PUZZLE GAME WITH A* ALGORITHM BASED ON ANDROID}

\begin{abstract}
Chemical elements are a subject in high school levels However, the abstract table of chemical elements often makes students lazy to memorize and remember a periodik table of chemical elements. To help students, one of them is by taking advantage of technological developments by making educational game applications in the form of 2- dimensional puzzle games. This application program is intended to help students hone their memory on the periodik table of chemical elements by arranging the randomized table arrangement into a complete table. Users can choose the level of play freely according to what they want. The program uses a-star algorithm and applies heuristic methods. The a-star algorithm can solve the problem optimally to find ... the shortest path to the goal. The application of the heuristic method is used to directly sort the results obtained without having to follow all paths. The test results show all the features and the implementation of the algorithm in this game application are running properly.
\end{abstract}

Keywords - A-star Algorithm, Puzzle Game, Periodik Table of Chemical Elements.

\section{Pendahuluan}

Saat ini permainan game mengalami perkembangan yang sangat pesat [1]. Salah satu jenis game adalah game puzzle, game ini akan menyusun susunan gambar menjadi gambar yang utuh. Game atau permainan merupakan suatu jenis pertandingan yang bertujuan untuk hiburan dan sebagai media untuk belajar atau sebagai media pendidikan yang menghibur [2][3]. Game edukasi merupakan permainan digital yang dirancang sebagai media pembelajaran dengan menggunakan teknologi multimedia yang interaktif [4]. Selain itu, 
game edukasi ini memiliki kelebihan yaitu dengan menyajikan visualisasi yang menarik dibandingkan dengan metode metode pembelajaran yang konvensional [5]. Game yang menampilkan fitur yang menarik dan interaktif ini dapat dijadikan sebagai salah satu alternative untuk pembelajaran sehingga materi pelajaran dapat dengan mudah di pahami oleh siswa. Cabang dari Ilmu Pengetahuan Alam atau biasa disebut IPA, salah satunya yaitu ilmu kimia yang mencakup teori, konsep, hukum, aturan, dan prinsip. Terdapat beberapa karakteristik pada ilmu kimia diantaranya yaitu bersifat abstrak, konsep yang merupakan penyederhanaan dari keadaan sebenarnya, dan konsep kimia yang bersifat berurutan dan berkembang dengan cepat. Dengan karakteristik ilmu kimia tersebut menyebabkan kimia dianggap sulit [6]. Pada cabang IPA terdapat sistem periodik unsur yang merupakan suatu susunan unsur senyawa kimia yang disusun dengan aturan tertentu. Unsur senyawa yang terdapat pada tabel sistem periodik dikelompokan dalam suatu golongan dan periode suatu senyawa [7]. Oleh karena itu, diperlukan adanya media alternative untuk dapat mengasah daya ingat dan memahami suatu tabel periodik unsur kimia dengan melalui game edukasi yang berbentuk puzzle. The tabperi yaitu sebuah program aplikasi yang dapat membantu penggunanya dalam mengasah daya ingat suatu tabel periodik unsur kimia.

Teknik pencarian yang digunakan pada penelitian ini adalah pencarian heuristik. Pencarian heuristik merupakan metode pencarian dengan meminimalisir jalur lintasan yang tidak diperlukan, dimana pencarian menggunakan algoritme A-star. Beberapa penelitian terkait dengan penyajian pembelajaran yang interaktif untuk memudahkan siswa dalam memahami materi sudah dilakukan dan hasil dari penelitian tersebut telah membuat siswa mudah dalam memahami materi tersebut [8]. Begitupun penelitian tentang pembuatan game edukasi untuk pembelajaran sudah dilakukan, dan hasilnya dengan menggunakan game tersebut siswa menjadi lebih mempermudah siswa dalam mempelajari materi yang diberikan [9]. Sedangkan penelitian yang terkait dengan teknik pencarian yang menggunakan algoritme A-star sudah dihasilkan bahwa bahwa algoritme ini dapat menemukan jalan terpendek tanpa harus menyelusuri semua jalan lintasan untuk mencapai tujuan [10]. Namun fungsi heuristik digunakan sebagai perkiraan dan tidak memiliki rumus khusus.
Artinya, dalam setiap kasus fungsi heuristik ini akan berbeda-beda.

Pada penelitian ini aplikasi yang dibuat dijalankan pada sistem operasi android di perangkat smartphone. Android merupakan system operasi yang digunakan pada perangkat mobile berbasis Linux [11][12]. Tujuan di buatnya aplikasi ini adalah untuk memudahkan pengguna dalam hal ini adalah pelajar dalam memahami dan meningkatkan daya ingat khususnya pada tabel periodik unsur kimia, serta dapat meningkatkan antusiasme masyarakat dalam memilih suatu game yang memiliki unsur edukatif agar penggunaan game lebih berguna .

\section{METODE DAN BAHAN}

Pada penelitian ini menggunakan metode heuristik untuk meminimalisir suatu jalan lintasan dari node awal ke node tujuan tanpa harus menyelusuri semua jalan lintasan secara selektif [13]. Dimana metode algoritme yang digunakan dalam pencarian ini adalah algoritme A-star. Algoritme A-star yaitu pengembangan dari algoritme best first search. Perbedaannya terletak pada biaya perkiraan $(\mathrm{h}(\mathrm{n}))$. Untuk best first search hanya menggunakan biaya perkiraan atau estimasi sedangkan pada algoritme a-star terdapat tambahan biaya sesungguhnya $(\mathrm{g}(\mathrm{n}))$. Dengan fungsi heuristik, maka fungsi algoritme A-star dapat menjadi lebih optimal [14]. Secara sistematis ditulis dengan persamaan 1, yaitu :

$$
\mathrm{f}(\mathrm{n})=\mathrm{g}(\mathrm{n})+\mathrm{h}(\mathrm{n})
$$

dengan:

$\mathrm{f}(\mathrm{n})=$ sebagai fungsi evaluasi

$\mathrm{g}(\mathrm{n})=$ sebagai biaya yang sebenarnya yang sudah dikeluarkan dari node awal hingga node tujuan $h(n)=$ sebagai biaya estimasi

Pembuatan game 2D pada game The Tabperi ini menggunakan aplikasi Unity dengan memakai bahasa pemrograman C\#. Unity merupakan sebuah aplikasi pengembang game yang dapat menciptakan game 2 dimensi dan 3 dimensi serta dapat membuat tombol gerakan dan aksi pada platform game [15].

Pada penelitian ini, penulis menerapkan metode waterfall yang merupakan model pengembangan aplikasi yang sekuensial dan sistematis [16]. Alasan menggunakan metode ini yaitu pelaksanaanya dilakukan secara terstruktur dan jelas. Tahapan dari pengembangan sistem pada model waterfall yaitu sebagai beikut:

a. Analisis Kebutuhan 
Analisis kebutuhan merupakan proses analisa kebutuhan sistem. Penulis mengumpulkan data dengan cara observasi dan studi ke perpustakaan.

b. Perancangan

Proses perancangan, programmer mengalokasikan kebutuhan - kebutuhan sistem meliputi penggambaran data yang akan diproses.

c. Implementasi

Pada tahap ini bertujuan membuat sistem serta merealisasikan perangkat lunak yang telah dirancang sebagai program.

d. Pengujian

Setelah pengimplementasian, maka dilakukan pengujian sistem yang bertujuan untuk memastikan aplikasi sudah sesuai dengan kebutuhan perangkat lunak.

e. Analisis dan Kesimpulan

Tahap ini merupakan tahap pembutan laporan dari hasil perancangan dan pembangunan perangkat lunak. Kemudian dilakukan analisis pada sistem dan membuat kesimpulan.

Aplikasi yang dibangun menggunakan pendekatan objek, sehingga untuk menganalisis kebutuhan dari aplikasi yang dibuat menggunakan tools Unified Modeling Language (UML). UML merupakan teknik untuk pemodelan sistem atau perangkat lunak yang berorientasi objek [17].

Adapun beberapa proses yang ada diaplikasi yang dibuat dapat dilihat pada tebel 1. Gambaran aktivitas pengguna terhadap aplikasi yang dibuat dapat dilihat pada gambar 1 .

Dari gambar 1, pengguna dapat memilih dengan bebas menu mana yang akan dipilih. Untuk menu level mudah dan level sulit cara bermainnya tetap sama yaitu dengan menyusun susunan tabel periodi unsur kimia dengan menyusunnya menjadi susunan yang utuh. Pada kedua level tersebut hanya dibedakan dengan warna saja, untuk menu level mudah puzzle diberi warna sesuai dengan tabel aslinya sehingga dapat mengelompokan sesuai dengan warna atau golongan dari senyawa. Sedangkan untuk menu level sulit disusun dengan warna hitam putih saja, sehingga pengguna lebih sulit untuk mengelompokan dan menyusun tabel. Pada aplikasi ini juga pengguna juga dapat melihat score hasil dari setiap permainan yang dilakukan.
Tabel 1. Kebutuhan Proses di Aplikasi

\begin{tabular}{|c|c|}
\hline Proses & Keterangan \\
\hline $\begin{array}{l}\text { Proses } \\
\text { menampilkan teori }\end{array}$ & $\begin{array}{l}\text { Tabel periodik } \\
\text { unsur kimia yang } \\
\text { digunakan } \\
\text { pengguna dalam } \\
\text { membantu } \\
\text { permainan }\end{array}$ \\
\hline $\begin{array}{l}\text { Proses permainan } \\
\text { level mudah }\end{array}$ & $\begin{array}{l}\text { Permainan } \\
\text { menyusun unsur } \\
\text { kimia untuk level } \\
\text { mudah }\end{array}$ \\
\hline $\begin{array}{l}\text { Proses permainan } \\
\text { level sulit }\end{array}$ & $\begin{array}{l}\text { Permainan } \\
\text { menyusun unsur } \\
\text { kimia untuk level } \\
\text { sulit }\end{array}$ \\
\hline $\begin{array}{l}\text { Proses drag potongan } \\
\text { puzzle }\end{array}$ & $\begin{array}{l}\text { Penyusunan puzzle } \\
\text { unsur kimia }\end{array}$ \\
\hline Proses hitung score & $\begin{array}{l}\text { Menampilkan hasil } \\
\text { score dari } \\
\text { permainan }\end{array}$ \\
\hline
\end{tabular}

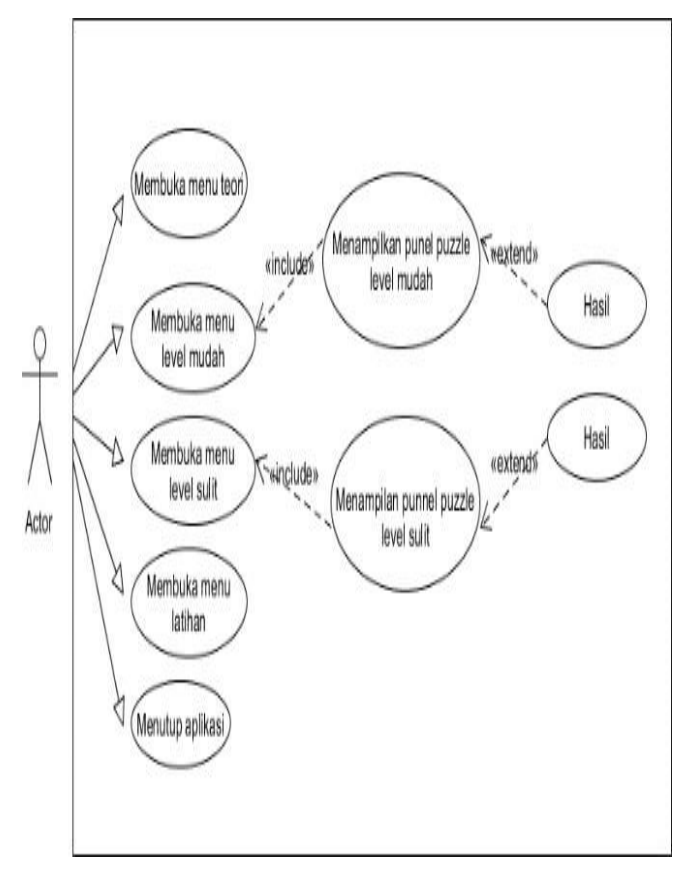

Gambar 1. Use Case Diagram Aplikasi

Rancangan antar muka dari aplikasi yang dibuat dapat dilihat pada gambar 2, 3, dan 4. Pada gambar 2 merupakan gambar rancangan dari menu utama game 
puzzle The Tabperi. Pada tampilan tersebut pengguna dapat memilih proses - proses yang dilakukan di aplikasi seperti proses permainan level mudah, level sulit, dan latihan.

Pada gambar 3 menunjukan rancangan untuk menampilkan tabel periodik yang dapat membantu pengguna dalam melakukan permainan.

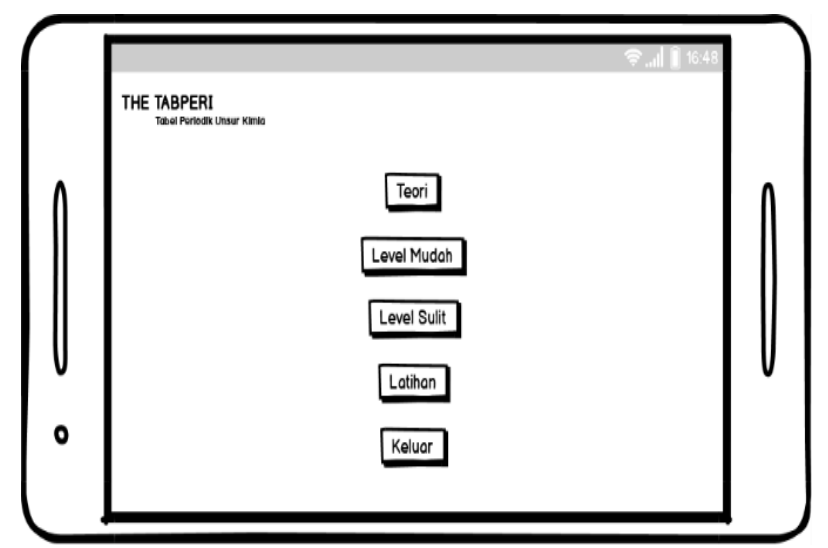

Gambar 2. Perancangan Menu Utama

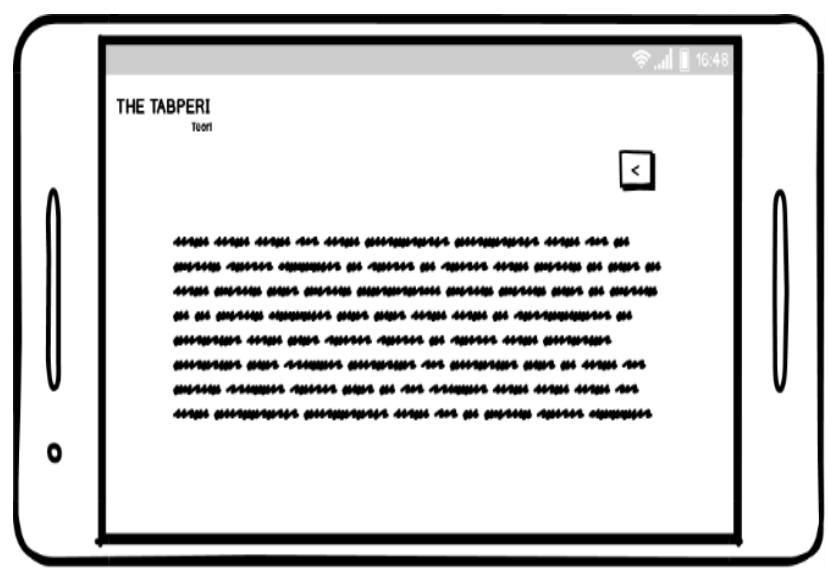

Gambar 3. Perancangan Menu Teori

Pada gambar 4 merupakan rancangan dari tampilan panel puzzle menu level mudah dan level sulit. Pengguna akan memainkan permaiman didalam menu ini. Pada gambar 5 merupakan rancangan dari tampilan score yang didapat oleh pengguna setelah memainkan game puzzle.

Untuk pengujian terhadap aplikasi yang dibuat menggunakan pengujian alpha dan betha. Pengujian alpha dilakukan untuk melihat apakah fungsional yang ada pada aplikasi sudah berjalan sesuai dengan analisis kebutuhannya, sedangkan pengujian betha dilakukan untuk melihat apakah aplikasi sudah sesuai dengan kebutuhan pengguna. Tahap pengujian aplikasi terhadap pengguna dilakukan dengan menggunakan pendekatan berupa penyebaran kuisioner dengan memberikan pertanyaan mengenai aplikasi yang sudah dibuat, adapun isi wawancara dapat dilihat pada tabel. Pengguna aplikasi ini adalah 30 orang siswa sekolah menengah ke atas yang mempelajari mata pelajaran kimia dan harus harus memiliki smartphone android. Pengguna diberikan penjelasan tentang tujuan penelitian dan cara penggunaan aplikasi. Pengguna diminta untuk mencoba aplikasi tersebut, kemudian diminta untuk menjawab serangkaian pertanyaan. Setelah mendapatkan jawaban atas pertanyaan pengguna, langkah selanjutnya adalah menganalisis jawaban. Tahapan pengujian dari aplikasi dapat dilihat pada gambar 6.

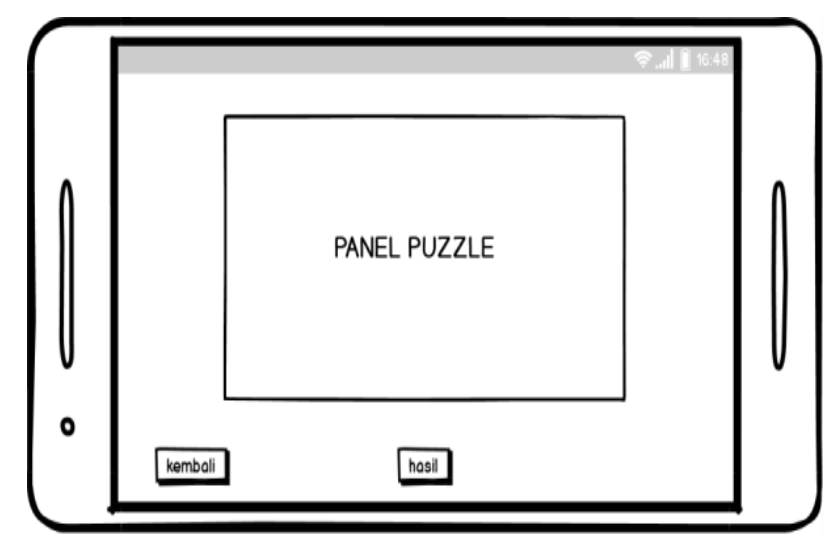

Gambar 4. Perancangan Menu Level Mudah

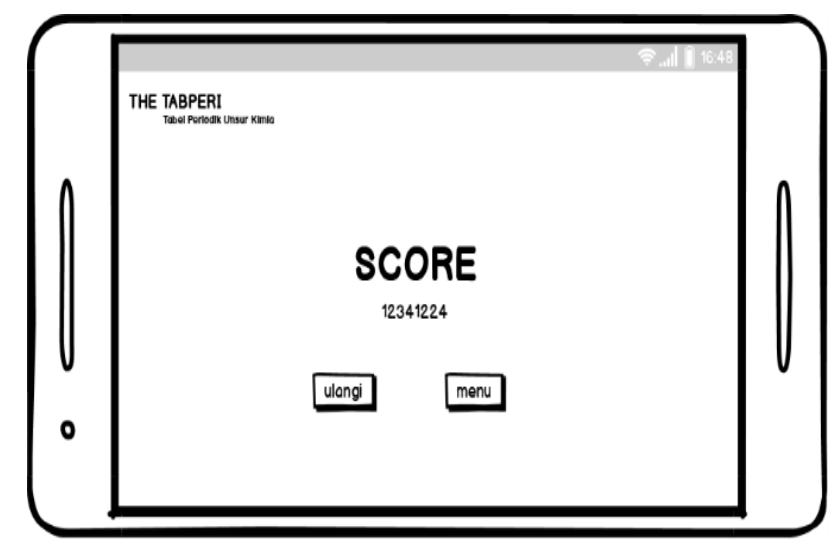

Gambar 5. Perancangan Tampilan Score 


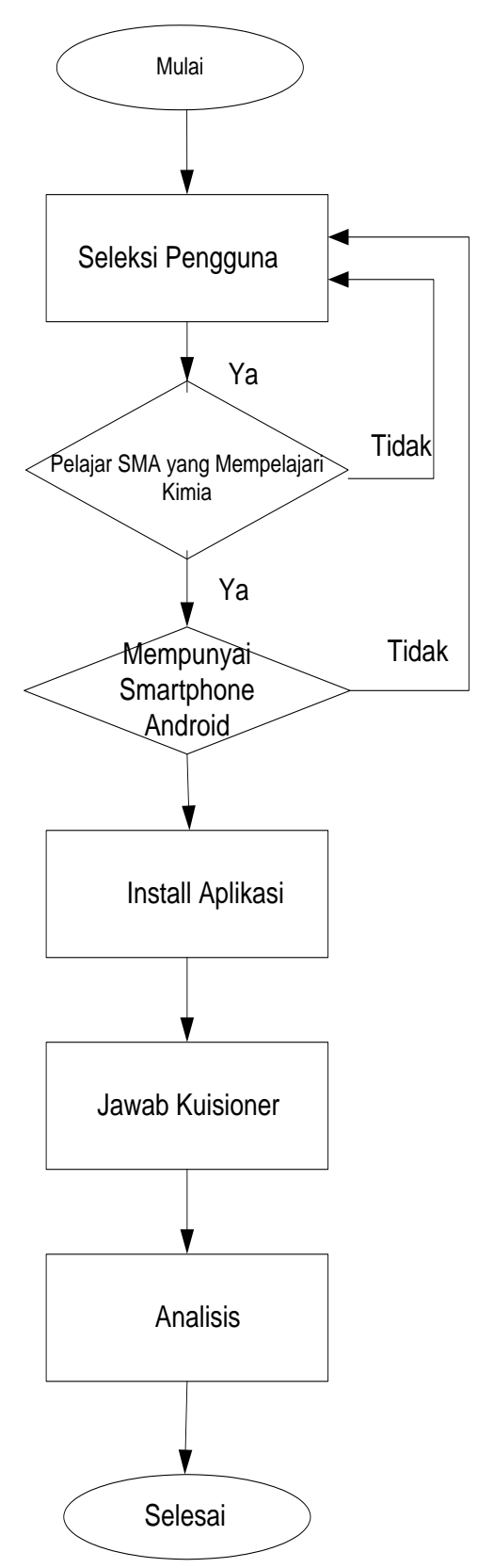

Gambar 6. Tahapan Pengujian Aplikasi

\section{HASIL DAN PEMBAHASAN}

Berdasarkan analisis dan perancangan yang telah dijabarkan, hasil implementasi antar muka dapat dilihat pada gambar 7, 8, 9, 10, dan 11 .

Gambar 7, merupakan tampilan dari menu utama dari game puzzle The Tabperi. Didalam menu utama terdapat menu yang dapat dipilih oleh pengguna yaitu menu teori, menu level mudah, menu level sulit, dan menu latihan.

Gambar 8, menunjukan menu teori yang berisi gambar tabel periodik secara utuh. Pengguna dapat melihat gambar tabel terlebih dahulu sebelum memainkan permainan agar pengguna dapat mengetahui bagaimana susunan tabel tersebut
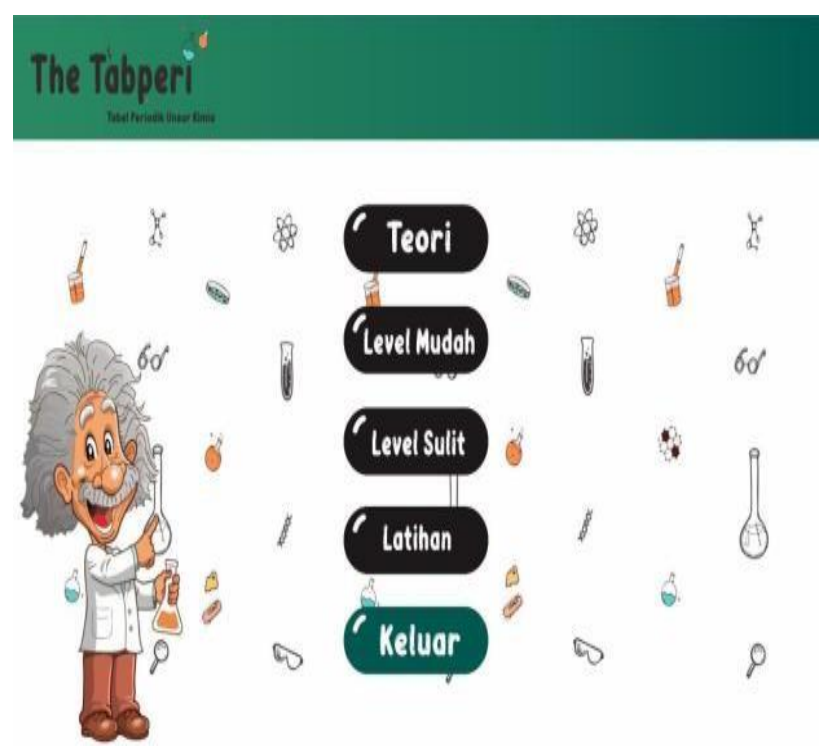

Gambar 7. Tampilan Menu Utama

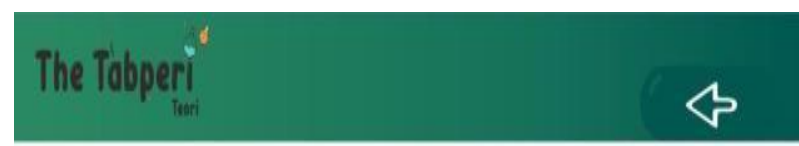

TABEL SISTEM PERIODIK UNSUR KIMIA

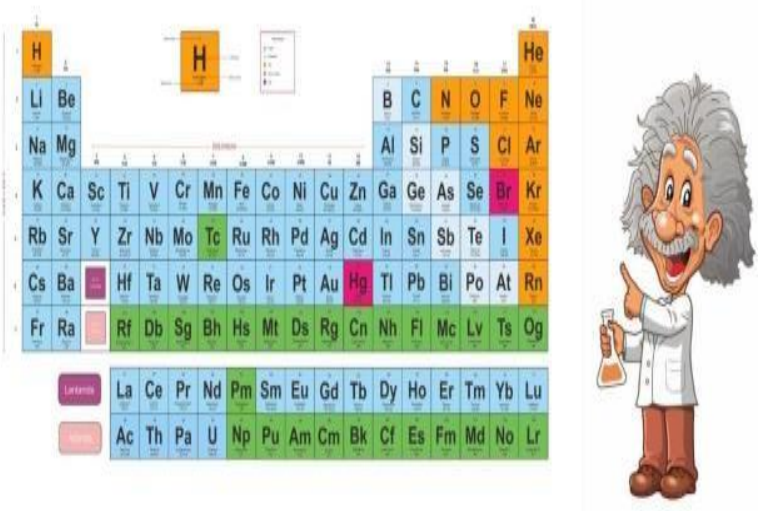

.Gambar 8. Tampilan Menu Teori

Gambar 9, yaitu tampilan dari menu level mudah. Pengguna dapat memainkan game puzzle dengan cara menyusun puzzle sesuai dengan warna dari unsur senyawa kimia. 
Gambar 10, menunjukan tampilan dari menu level sulit yang dimana ini memiliki tampilan dan fungsi yang sama dengan level mudah. Perbedaan terletak pada visual atau gambar tabel periodik yaitu pada level sulit berwarna hitam dan putih.

Gambar 11 merupakan tampilan score yang didapat oleh pengguna setelah pengguna menekan tombol hasil pada panel puzzle level mudah, level sulit maupun latihan. Jika pengguna ingin mengulangi game yang telah dimainkan, maka pengguna dapat menekan tombol "ulangi". Akan tetapi jika ingin

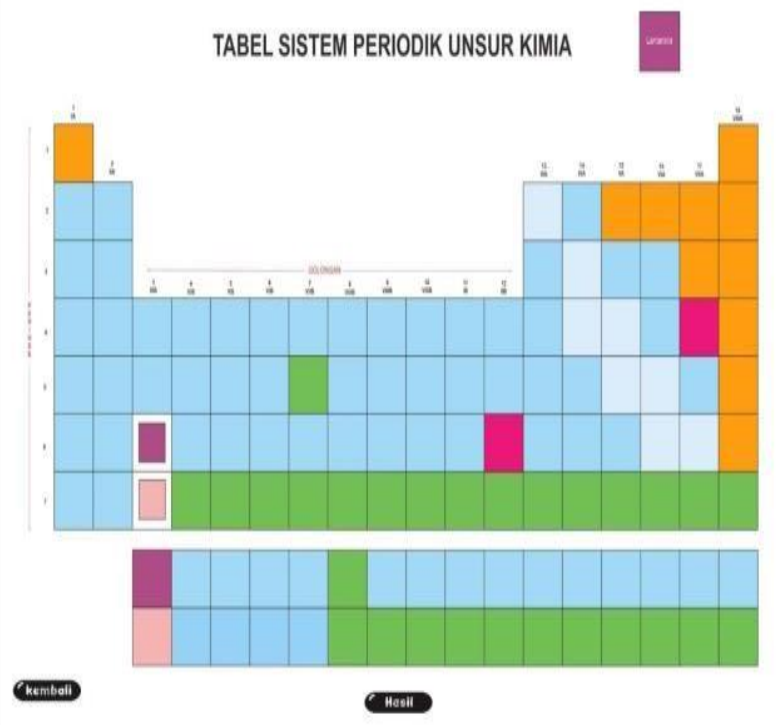

memilih menu lain maka pengguna dapat menekan tombol "keluar" agar dapat kembali pada menu utama.

Gambar 9. Tampilan menu level mudah

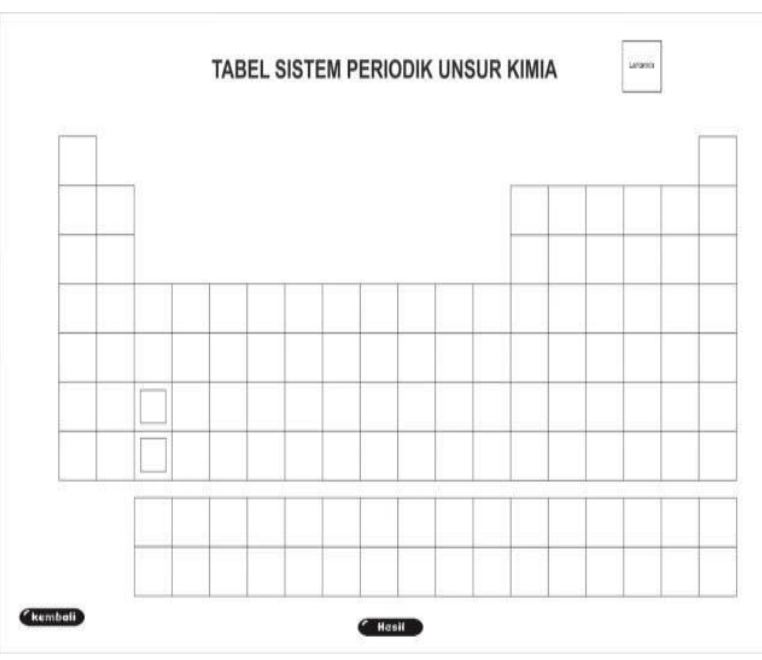

Gambar 10. Tampilan Menu Level Sulit
Dengan menggunakan metode blackbox untuk menguji fungsional yang ada di setiap aplikasi apakah sudah berjalan sesuai dengan yang telah dirancang sebelumnya, maka hasilnya dapat dilihat pada tabel 2.

Dari tabel 2, menunjukan bahwa setiap pengujian dari setiap butir uji fungsional yang ada pada aplikasi berhasil dijalankan. Hal ini menunjukan bahwa aplikasi sudah berjalan sesuai dengan analisis rancangan yang di lakukan sebelumnya, dan aplikasi sudah dapat digunakan untuk mempelajari susunan tabel periodik unsur kimia untuk pengguna yang mempelajari materi kimia khususnya susunan unsur kimia.

\section{TABEL SISTEM PERIODIK UNSUR KIMIA}

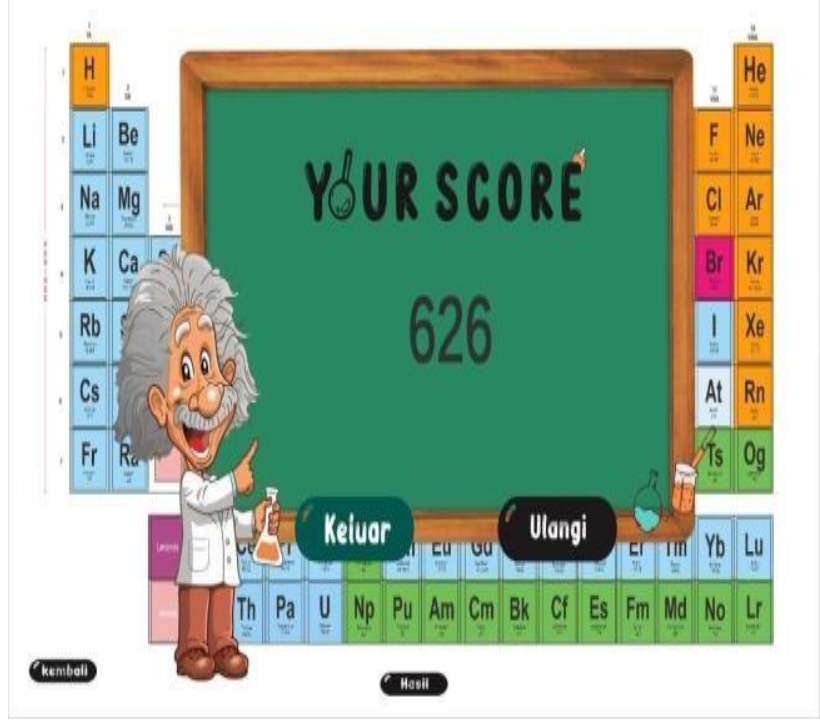

Gambar 11. Tampilan Score

Tabel 2. Hasil Pengujian Aplikasi

\begin{tabular}{ll}
\hline \multicolumn{1}{c}{ Butir Uji } & Hasil \\
\hline $\begin{array}{l}\text { Proses menampilakan } \\
\text { teori }\end{array}$ & Berhasil \\
$\begin{array}{l}\text { Proses permainan level } \\
\text { mudah }\end{array}$ & Berhasil \\
$\begin{array}{l}\text { Proses permainan level } \\
\text { sulit }\end{array}$ & Berhasil \\
$\begin{array}{l}\text { Proses latihan } \\
\text { Proses drag potongan puzzle } \\
\text { Proses hitung score }\end{array}$ & Berhasil \\
\hline
\end{tabular}

Pengujian untuk melihat kepuasan pengguna terhadap aplikasi yang dibuat dilakukan dengan 
menyebarkan kuisioner ke 30 pengguna, dimana pengguna disini adala pelajar sekolah menengah yang mempelajari pelajarana kimia. Mereka semua memiliki pengalaman menggunakan aplikasi seluler.

Tabel 3. Mengetahui game puzzle

\begin{tabular}{lc}
\hline \multicolumn{2}{c}{ User $(\mathrm{n}=30)$} \\
\hline Sangat tidak setuju \\
\hline Tidak setuju \\
\hline Ragu - ragu & \\
\hline Setuju & 27 \\
\hline Sangat setuju & 3 \\
\hline
\end{tabular}

Dari tabel 3 menunjukan bahwa 27 pengguna menyatakan sudah mengetahui game puzzle, ini menunjukkan pengguna sudah terbiasa dengan game puzzle yang artinya jika diberikan pengenalan unsur kimia menggunakan puzzle pengguna dapat menggunakannya.

Tabel 4. Aplikasi mudah dipahami

\begin{tabular}{lc}
\hline & User $(\mathrm{n}=30)$ \\
\hline Sangat tidak setuju & \\
\hline Tidak setuju & \\
\hline Ragu - ragu & 6 \\
\hline Setuju & 5 \\
\hline Sangat setuju & 19 \\
\hline
\end{tabular}

Tabel 5. Aplikasi membantu untuk menghapal susunan unsur periodik kimia

\begin{tabular}{lc}
\hline & User $(\mathrm{n}=30)$ \\
\hline Sangat tidak setuju & \\
\hline Tidak setuju & \\
\hline Ragu - ragu & 4 \\
\hline Setuju & 11 \\
\hline Sangat setuju & 14 \\
\hline
\end{tabular}

Dari tabel 4 dan 5 menunjukan bahwa 19 pengguna menyatakan bahwa setuju aplikasi mudah digunakan, sedangkan untuk pernyataan apakah aplikasi dapat membantu daya ingat untuk menghapal tabel periodik terdapat 14 pengguna menyatakan setuju membantu untuk mengingat susunan tabel periodik kimia. Dari hasil jawaban untuk pernyataan- pernyataan tersebut menyatakan bahwa pengguna diberikan kemudahan untuk mempelajari, menjadikan belajar tabel periodik unsur kimia lebih menari, dan juga dapat membantu mengingat susunan tabel periodik kimia.
3

\section{KESIMPULAN}

Berdasarkan hasil analisis penelitian serta pengujian pada aplikasi yang dibuat mengunalan pencarian algoritme agame puzzle the tabperi ini mendapat kesimpulan bahwa aplikasi game yang telah dirancang dan dibuat secara fungsional sudah berjalan sesuai dengan analisis kebutuhan dan memberikan kemudahan kepada pengguna untuk menghafal suatu tabel periodik unsur kimia.

\section{UCAPAN TERIMA KASIH}

Penulis berterima kasih kepada Universitas Komputer Indonesia pada pihak-pihak yang telah membantu serta memberi dukungan dalam penelitian ini.

\section{DAFTAR PUSTAKA}

[1] W. Hidayat, "Rancang Bangun Game Puzzle Menggunakan Platform Android. JUSTIN", Jurnal Sistem dan Teknologi Informasi, 2(1), 44-49, 2014.

[2] M. Yunus, I. F. Astuti, and D. M. Khairina, "Game Edukasi Matematika Untuk Sekolah Dasar," Inform.Mulawarman J. Ilm. Ilmu Komput., vol. 10, no. 2, p. 59, 2015.

[3] A. Gunadi and H. Al Fatta, "Analisis Dan Pembuatan Game 'Petualangan Si Argo' Berbasis Flash," Data Manaj. dan Teknol. Inf., vol. 13, no. 1, p. 42, 2012.

[4] N Indriani, and I Setiawan, "Membangun Game Edukasi Sejarah Walisongo", Jurnal Ilmiah Komputer dan Informatika KOMPUTA )," pp. 41-48, 2013.

[5] A. H Nugroho, and $R$ Komarudin, "Pengembangan Game Puzzle Berbasis Android sebagai Media Edukasi Pengenalan Pahlawan Nasional. Informatics For Educators And Professional: Journal of Informatics, 2(2), 149-158, 2018

[6] R. A Sari, S Saputro, and A.N.C Saputro, "Pengembangan Modul Pembelajaran Kimia Berbasis Blog untuk Materi Struktur Atom dan Sistem Periodik Unsur SMA Kelas XI", Jurnal Pendidikan Kimia, 3(2), 7-15, 2014. 
[7] I. F. Utami, K. I. Satoto, and K. T. Martono, “Teka-teki Unsur Kimia sebagai Media Pembelajaran Kimia Interaktif bagi siswa SMA Kelas X Berbasis Android,"

J. Teknol. dan Sist. Komput., vol. 4, no. 1, p. 139, 2016.

[8] S. Nurhayati, "Aplikasi Pembelajaran Interaktif Ilmu Pengetahuan Sosial Pada Smp Negeri 1 Carita", JOINS (Journal of Information System), 5(2), 200-207, 2021.

[9] U. Cahyana, M. Paristiowati, M.F. Nurhadi, and S. N Hasyrin, "Studi tentang motivasi belajar siswa pada penggunaan media mobile game base learning dalam pembelajaran laju reaksi kimia" JTP-Jurnal Teknologi Pendidikan, 19(2), 143-15.5, 2017.

[10] M. A Mustaqov, and D. A. Megawaty, "Penerapan Algoritme A-Star Pada Aplikasi Pencarian Lokasi Fotografi Di Bandar Lampung berbasis Android", Jurnal Teknoinfo, 14(1), 27-34, 2020.

[11] J. Kuswanto and F. Radiansah, "Media Pembelajaran Berbasis Android Pada Mata Pelajaran Sistem Operasi Jaringan Kelas XI," An Nabighoh J. Pendidik. dan Pembelajaran Bhs. Arab, vol. 14, no. 01, p. 129, 2018.

[12] S. Nurhayati, N. Milal, and A. P. Sujana, "Location Search Application for Refuelling Stations on Android Based Mobile Devices", In IOP Conference Series: Materials Science and Engineering (Vol. 879, No. 1, p. 012020). IOP Publishing, 2020.

[13] Y. M. Geasela, and J. F. Andry, "Analisis User Interface terhadap Website Berbasis ELearning dengan Metode Heuristic Evaluation", Jurnal Informatika, 5(2), 270-277, 2018.

[14] Yuliana, Ananda, and I Surya, "Implementasi Algoritme A Star pada Pemecahan Puzzle 8," J. Tek. Inform., vol. 1, no. September, pp. 1-9, 2012.

[15] S. Nasution, A. H. Nasution, and A. L. Hakim, "Pembuatan Plugin Tile-Based Game Pada Unity 3D," It J. Res. Dev., vol. 4, no. 1, pp. 46-60, 2019.

[16] G. W. Sasmito, "Penerapan Metode Waterfall Pada Desain Sistem Informasi Geografis Industri Kabupaten Tegal", Jurnal Informatika: Jurnal Pengembangan IT, 2(1), 6-12, 2017.

[17] H. L. H. S. Warnars, "Pemodelan Elearning Perguruan Tinggi Dengan Menggunakan
Framework Learning Technology System Architecture (Ltsa) Dan Unified Modeling Language (Uml)," JUTI J. Ilm. Teknol. Inf., vol. 15 , no. 1, p. $43,2017$. 